\title{
Immunomodulation of MSCs and MSC-Derived Extracellular Vesicles in Osteoarthritis
}

OPEN ACCESS

Edited by:

Liyuan Zhang,

Harvard University, United States

Reviewed by:

Emilie Velot,

Université de Lorraine, France

Jae-Won Shin,

University of Illinois at Chicago,

United States

*Correspondence:

Xing Wang

wangxing@iccas.ac.cn

Qiang Yang

yangqiang1980@126.com

tThese authors have contributed equally to this work

Specialty section:

This article was submitted to Biomaterials,

a section of the journal

Frontiers in Bioengineering and

Biotechnology

Received: 22 June 2020 Accepted: 21 September 2020

Published: 29 October 2020

Citation:

Zhao $X$, Zhao $Y$, Sun $X$, Xing $Y$,

Wang $X$ and Yang $Q$ (2020)

Immunomodulation of MSCs and

MSC-Derived Extracellular Vesicles in

Osteoarthritis.

Front. Bioeng. Biotechnol. 8:575057.

doi: 10.3389/fbioe.2020.575057

\begin{abstract}
Xige Zhao ${ }^{1 \dagger}$, Yanhong Zhao ${ }^{1 \dagger}$, Xun Sun ${ }^{2}$, Yi Xing ${ }^{1}$, Xing Wang ${ }^{3,4 *}$ and Qiang Yang ${ }^{2 *}$
${ }^{1}$ Stomatological Hospital of Tianjin Medical University, Tianjin, China, ${ }^{2}$ Department of Spine Surgery, Tianjin Hospital, Tianjin University, Tianiin, China, ${ }^{3}$ Beijing National Laboratory for Molecular Sciences, Institute of Chemistry, Chinese Academy of Sciences, Beijing, China, ${ }^{4}$ University of Chinese Academy of Sciences, Beijing, China
\end{abstract}

Osteoarthritis (OA) has become recognized as a low-grade inflammatory state. Inflammatory infiltration of the synovium by macrophages, T cells, B cells, and other immune cells is often observed in OA patients and plays a key role in the pathogenesis of OA. Hence, orchestrating the local inflammatory microenvironment and tissue regeneration microenvironment is important for the treatment of OA. Mesenchymal stem cells (MSCs) offer the potential for cartilage regeneration owing to their effective immunomodulatory properties and anti-inflammatory abilities. The paracrine effect, mediated by MSC-derived extracellular vehicles (EVs), has recently been suggested as a mechanism for their therapeutic properties. In this review, we summarize the interactions between MSCs or MSC-derived EVs and OA-related immune cells and discuss their therapeutic effects in OA. Additionally, we discuss the potential of MSC-derived EVs as a novel cell-free therapy approach for the clinical treatment of OA.

Keywords: osteoarthritis, MSCs, exosomes, immunomodulatory, macrophage

\section{INTRODUCTION}

Osteoarthritis $(\mathrm{OA})$ is a chronic degenerative joint disease that affects about $15 \%$ of the global population (Loeser, 2013; Hunter and Bierma-Zeinstra, 2019). OA involves not only the knees but also the spine, hands, and temporal-mandibular joints and is characterized by the articular cartilage degradation, synovitis, subchondral bone remodeling, and osteophyte formation. Patients experience aggravating pain and disability, resulting in decreased life quality and a high economic burden. The traditional viewpoint is that OA is a non-inflammatory disease. However, studies have shown that there is a type of chronic, low-grade inflammation in the pathogenesis of $\mathrm{OA}$, which seriously hinders the proliferation of chondrocytes and the deposition of cartilage matrix, resulting in low efficiency of repair (Aspden and Saunders, 2019; Chow and Chin, 2020; Woodell-May and Sommerfeld, 2020). Various immune cells have been identified in the synovium of OA patients. Among them, macrophages, $\mathrm{T}$ cells, and B cells are the most abundant (de Lange-Brokaar et al., 2012).

Synovial macrophages $(\mathrm{M} \varphi)$ are the main immune cells in joints (Fernandes et al., 2020; Wu C. L. et al., 2020). Historically, macrophages have been characterized as classically activated macrophages, or proinflammatory macrophages $(\operatorname{M1M} \varphi)$, and are activated by interferon- $\gamma$ (IFN- $\gamma)$, tissue necrosis factor- $\alpha$ (TNF- $\alpha$ ), or pathogen-associated molecular patterns. Once activated, these macrophages secrete proinflammatory cytokines such as interleukin-1 (IL-1), IL-6, IL-12, and inducible nitric oxide synthase. Conversely, anti-inflammatory macrophages 
$(\mathrm{M} 2 \mathrm{M} \varphi)$ are activated by an alternative activation pathway. These macrophages release growth and angiogenic factors such as transforming growth factor- $\beta$ (TGF- $\beta$ ) and arginase-1 (Arg1 ), which down-regulate inflammation and promote remodeling of damaged tissue (Wynn and Vannella, 2016; Oishi and Manabe, 2018). The spatiotemporal distribution of M1 and $\mathrm{M} 2 \mathrm{M} \varphi$ plays a key role in the orchestration of inflammation and tissue regeneration (Zhang H. Y. et al., 2018; Fernandes et al., 2020). It has been thought that depletion of $\mathrm{M} \varphi$ can eliminate inflammation and further alleviate the progression of OA. For this reason, $\mathrm{Wu}$ et al. used the macrophage Fasinduced apoptosis (MaFIA) transgenic mice. They placed the MaFIA mice on a high-fat diet and induced knee OA and then conditional macrophage exhaustion in synovium tissue. The results showed that OA with obesity was not attenuated by macrophage depletion of both M1 and M2 types. On the contrary, inflammatory cytokine production was intensified, which induced an increase of joint synovitis and cartilage damage (Wu et al., 2017). Given that $\mathrm{M} 1 \mathrm{M} \varphi$ is involved mainly in the initiation of inflammation, yet $\mathrm{M} 2 \mathrm{M} \varphi$ is involved mainly in the regression of inflammation, this phenomenon indicated that the failure of transformation from $\mathrm{M} 1 \mathrm{M} \varphi$ to $\mathrm{M} 2 \mathrm{M} \varphi$ may result in persistent chronic inflammation. At present, the implications of the alteration of the $\mathrm{M} \varphi$ polarization state for OA treatment are not clear, but several relevant studies have shown that infiltrative $\mathrm{M} 1 \mathrm{M} \varphi$ and $\mathrm{M} 2 \mathrm{M} \varphi$ exert different effects on cells within the joint, thus playing a key role in the orchestration of inflammation and regeneration (Blom et al., 2007; Fahy et al., 2014; Fichadiya et al., 2016; Utomo et al., 2016; Samavedi et al., 2017; Hu et al., 2018; Chen et al., 2020).

$\mathrm{T}$ cells are lymphocytes that represent the second main constituents of synovial infiltrates in OA patients. $\mathrm{T}$ cells can be broadly divided into helper $\mathrm{T}$ cells $\left(\mathrm{T}_{\mathrm{H}}\right.$ cells), cytotoxic $\mathrm{T}$ cells (Tc cells), and regulatory $\mathrm{T}$ cells (Tregs) according to their different functions, and the first two are collectively known as effector $\mathrm{T}$ cells. Previous studies have shown that both $\mathrm{CD}^{+}$(mainly differentiated into $\mathrm{T}_{\mathrm{H}}$ cells after activation) and $\mathrm{CD}^{+}$T-cell subsets (mainly differentiated into Tc cells after activation) have been found at higher levels not only in synovial fluid and membranes but also in peripheral blood (Haynes et al., 2002; Hussein et al., 2008; Labinsky et al., 2020), which suggests that $\mathrm{T}_{\mathrm{H}}$ cells and Tc cells are involved in the pathogenesis of OA (Raphael et al., 2015). Specifically, OA synovial tissue exhibits increased levels of $\mathrm{T}_{\mathrm{H}} 1$ (CD4 ${ }^{+} \mathrm{IFN}-\gamma^{+} \mathrm{T}$ cells), $\mathrm{T}_{\mathrm{H}} 17$ (CD4 ${ }^{+} \mathrm{IL}-17^{+} \mathrm{T}$ cells), and $\mathrm{Tc}\left(\mathrm{CD}^{+} \mathrm{T}\right.$ cells), whereas the synovial fluid has increased levels of $\mathrm{T}_{\mathrm{H}} 1, \mathrm{~T}_{\mathrm{H}} 9\left(\mathrm{CD} 4^{+} \mathrm{IL}^{+} \mathrm{T}\right.$ cells) and $\mathrm{T}_{\mathrm{H}} 17$ cells. $\mathrm{T}_{\mathrm{H}} 1$ produce IL-2, IFN- $\gamma$, TNF- $\alpha$, lymphotoxins, and granulocytemacrophage colony-stimulating factor Inflammatory cytokines, which exacerbate joint inflammation and recruit more effector $\mathrm{T}$ cells to inflammatory tissues, thus causing tissue damage (Li et al., 2017). $T_{H} 9$ cells preferentially produce IL-9, which is positively correlated with OA index (Qi et al., 2016). $\mathrm{T}_{\mathrm{H}} 17$ cells mainly produce IL-17 and IL-23, and the overexpression of the two cytokines promotes the infiltration of the immune cells, secretion of vascular endothelial growth factor, and growth of the blood vessel, thus aggravating cartilage degeneration (Bommireddy and
Doetschman, 2007). Tc cells also have been found to significantly shape the pathogenesis of OA; however, the exact role of them response in the biology of $\mathrm{OA}$ is still unclear (Hsieh et al., 2013). Under the induction of TGF- $\beta$, naive T cells differentiate into Tregs. Tregs are important immunomodulators in many inflammatory and autoimmune diseases, as they inhibit the immune response and maintain immune tolerance by secreting cytokines such as TGF- $\beta$, IL-10, and IL-35. Tregs exhibit a decreased response in the pathogenesis of OA (Hori et al., 2003; Bommireddy and Doetschman, 2007). Besides, the role of $\mathrm{T}_{\mathrm{H}}$ 17/Treg ratio in the immunoregulation of $\mathrm{OA}$ has also attracted increasing attention. It was found that if $\mathrm{T}_{\mathrm{H}} 17 /$ Treg ratio is deviated in favor of proinflammatory $\mathrm{T}_{\mathrm{H}} 17$ cells, arthritis was exacerbated (Noack and Miossec, 2014; Yang et al., 2018; Min et al., 2019; Peter et al., 2020) (Figure 1).

In the case of $\mathrm{OA}$, if the decomposition products of the cartilage matrix are exposed, B cells can be stimulated to produce autoantibodies and activate humoral immunity (Zhu et al., 2020), leading to disturbance of the entire articular environment. In such cases, autoantibodies against cartilage mesothelin, osteopontin, ykl-39, collagen, and proteoglycan have been detected (Ozeki et al., 2016). The harmful effects of autoantibody formation may lie in its diffusion and deposition in articular cartilage as an immune complex, which makes it easy to degrade and destroy. This may stimulate the complement system to clear the complex and become part of the complex pathogenic circuit that causes tissue damage (Modinger et al., 2019) (Figure 1).

Therefore, the treatment of OA should focus not only on "cartilage wear" but also on the immune cells that have a major impact on the occurrence and development of OA. Regulating the local inflammatory microenvironment and tissue regeneration microenvironment is important in the treatment of OA. Mesenchymal stem cells (MSCs) with self-renewal capacity and multidifferentiation potential have received much attention as an alternative approach in the management of cartilage degradation (Barry and Murphy, 2013; Fernandez-Pernas et al., 2020). Moreover, MSCs have been shown to possess effective immunomodulatory properties in the treatment of inflammatory diseases (Guillamat-Prats et al., 2017; de Castro et al., 2019; Zhao L. et al., 2019) and are capable of regulating the immune cells that play a pathogenic role in the progression of OA. In recent years, the paracrine effect of MSCs mediated by extracellular vehicles (EVs) has been suggested to explain their curative effect (Kalluri and LeBleu, 2020). Three main types of EVs have been described based on their biogenesis and size: exosomes (30-150 nm in diameter), microvesicles/microparticles, and apoptotic bodies (both considered to be $>100 \mathrm{~nm}$ ). Exosomes are secreted to the extracellular environment through the fusion of multivesicular bodies with the plasma membrane. The last two types of vesicles are released through forward budding of the plasma membrane in living and dying cells, respectively (Bui et al., 2018; Kalluri and LeBleu, 2020). EVs, as a natural and efficient transport carrier, can maintain functional characteristics similar to their parent cells (Bui et al., 2018; Wu X. et al., 2020). This insight has given rise to a new paradigm wherein EVs are collected from MSCs and used to actively regulate complicated communication among 


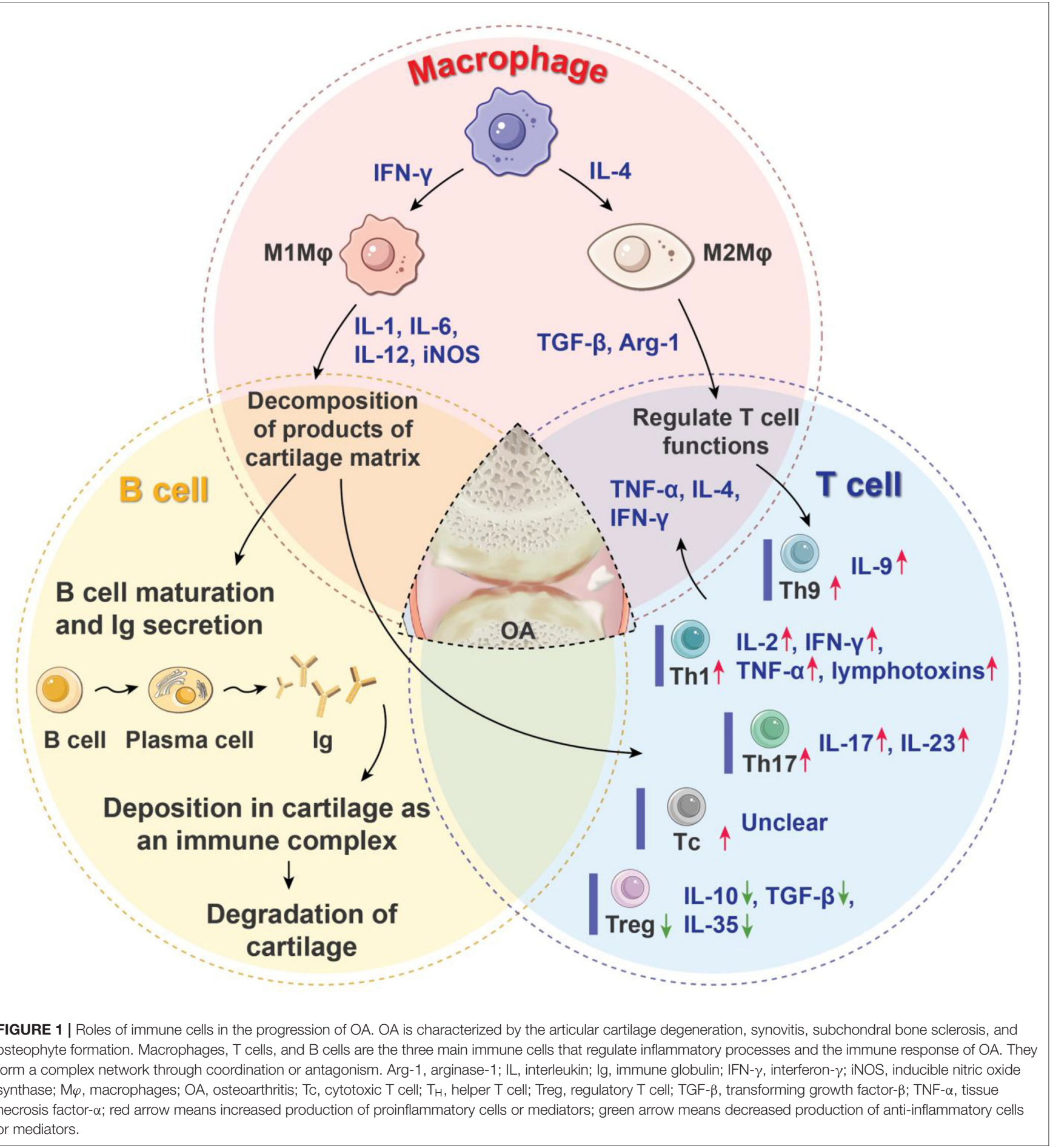

components of the immune system (Wang et al., 2018). The cellfree nature of EVs suggests that they may have a more favorable safety profile than cell-based therapies.

Within this review, we summarize and discuss what is known about the interactions of MSCs or MSC-derived EVs with OArelated immune cells and the importance of these interactions in therapeutic strategies for OA.

\section{ROLES OF MSCS IN IMMUNOMODULATION}

MSCs have immunomodulatory properties relying on both cellto-cell contact and paracrine signaling. Furthermore, under the local inflammatory microenvironment, low or high levels of specific toll-like receptor (TLR) ligands may greatly influence the 
immunoregulatory characteristics of MSCs and thereby impact the effect of MSC-based therapies (Lei et al., 2011). In the early stage of $\mathrm{OA}$, the molecules produced by damaged tissue or pathogens will be recognized by TLR2/4 (differences by species may exist) on the surface of MSCs, lead to MSCs polarization into MSC1 (Tomchuck et al., 2008). This phenotype can promote the immune response in the early stage of inflammation. This kind of acute inflammatory response after injury can induce the accumulation of inflammatory cells in the damaged area and play a role of automatic debridement, which has characteristics of protecting the joint tissue. However, persistent chronic inflammation is harmful to joints (Huang and Kraus, 2016). Accordingly, in the late stage of inflammation, the high levels of TLR3 ligand lead to MSCs transform to the inflammationdampening MSC2 phenotype to prevent prolonged damage to joints (Ayala-Cuellar et al., 2019). Failure of transformation in the stage of inflammation abatement during $\mathrm{OA}$ is the key to the continuation of the pathological vicious circle. In this case, joint resident MSCs may not be as effective as infused MSCs in restoring immunological and regenerative homeostasis in the degenerative joint. Therefore, in this section, we summarize the major studies investigating the effects of adoptive transferred MSCs during OA or other chronic degenerative diseases with chronic inflammation, focusing mainly on their immunosuppressive properties.

\section{Immunomodulatory Effect of MSCs on Macrophages}

MSCs can produce various growth factors, chemokines, and other signaling molecules affecting macrophage polarization, maturation, proliferation, and migration, which have been verified by MSC secretome analyses (Vizoso et al., 2017; Lin and Du, 2018).

Recent studies have revealed the ability of MSCs to regulate macrophage polarization by inducing a transformation from the M1 to the M2 phenotype, thus promoting the healing process (Cho et al., 2014). Abumaree et al. co-cultured "fried egg-like" M1 macrophages with MSCs for 3 days, and the cells gradually turned into "spindle-like" M2 macrophages (Abumaree et al., 2013). This process is accompanied by high-level secretion of IL-10, low levels of IL-12 and IL-1 $\beta$, and increased phagocytic activity. MSCs can also regulate the immune phenotype of macrophages in vivo, which has been demonstrated in a variety of disease models. For example, MSCs can prolong corneal allograft survival by altering M1/M2 polarization and inhibiting the infiltration of antigen-presenting cells (APCs) (Murphy et al., 2016).

At present, the mechanism by which MSCs regulate the phenotypic transformation of macrophages is not fully understood. Several studies have confirmed that MSCs affect macrophage polarization via direct cell contact and cytokines such as IL-10, prostaglandin E2 (PGE2), indoleamine 2,3dioxygenase (IDO), and TGF- $\beta$ secreted by MSCs (Park et al., 2018; Shi et al., 2019). IL-10 can promote the inflammatory repair of tissues, reduce inflammatory damage, and promote the transformation of macrophages to M2, which may be one of the main mechanisms of MSC-mediated macrophage transformation (Faulknor et al., 2017). PGE2 is another important antiinflammatory factor; it can combine with EP2 and EP4 receptors on the surface of macrophages, change the expression of downstream genes, and cause macrophages to transform into the M2 phenotype (Kawahara et al., 2015). The anti-inflammatory effect of macrophages is weakened by using specific PGE2 inhibitors, and the expression of IL-10 and IL- $1 \alpha$ in antiinflammatory cells also significantly decreases (Ylostalo et al., 2012). MSCs can also release IDO, which induces macrophages to transform into the M2 phenotype and release more IL-10. Lee et al. found that after treatment with the IDO-specific inhibitor 1-L-methyl-tryptophan (1-L-MT), the expression of IFN- $\alpha$ increased, and anti-inflammatory effects were significantly inhibited (Lee et al., 2016). TGF- $\beta 1$ is an important marker for M2 monocytes/macrophages. Liu et al. found that the inflammation was significantly attenuated after TGF- $\beta 1$ injection in colitis model mice (Jiang and Xu, 2020). Moreover, MSCs have also been reported to induce monocyte maturation directly to M2 macrophages by MSC secretion of IDO, IL-6, and PGE2 (Figure 2).

Collectively, these studies show that MSCs can induce macrophages to transform from the M1 to the M2 phenotype, inhibit proinflammatory cytokines, release antiinflammatory cytokines, reduce joint tissue damage, suppress the progress of inflammation, and promote the repair of inflammatory tissue.

\section{Immunomodulatory Effects of MSCs on T Cells MSCs Inhibit T-Cell Proliferation}

Nitric oxide (NO) secretion by mouse MSCs has been shown to regulate immunosuppression of T-cell responses directly by cell cycle arrest or apoptosis (Sato et al., 2007). Cytokines such as TGF- $\beta$ and hepatocyte growth factor secreted by MSCs can down-regulate the expression of cyclin D2 and up-regulate the expression of p27kip1 in $\mathrm{T}$ cells, resulting in cell cycle arrest in the G1 phase, thus inhibiting T-cell proliferation (Glennie et al., 2005; Kyurkchiev et al., 2014). PGE2 secreted by MSCs can also inhibit T-cell proliferation by decreasing IL-2 and down-regulating IL-2 receptor, leading to impaired DNA binding activity of transcription factors through inhibition of Janus kinase 3 signaling (Burr et al., 2013). Under stimulation by proinflammatory factors such as TNF- $\alpha$ and IFN- $\gamma$, MSCs can inhibit the proliferation of $\mathrm{T}$ cells and induce the apoptosis of activated $\mathrm{T}$ cells by producing IDO (Behm et al., 2020), an ironcontaining heme monomer membrane-binding protein that can catalyze the transformation of tryptophan into L-canine uric acid and picolinic acid. Tryptophan is an essential amino acid for the maintenance of T-cell activation and proliferation (Liu et al., 2016). The proliferation of $\mathrm{T}$ cells is blocked in the G1 phase if tryptophan concentration is low, resulting in the decrease of $\mathrm{T}$ cells. The tryptophan depletion mediated by IDO inhibits only activated T cells, not resting T cells (Figure 2). 


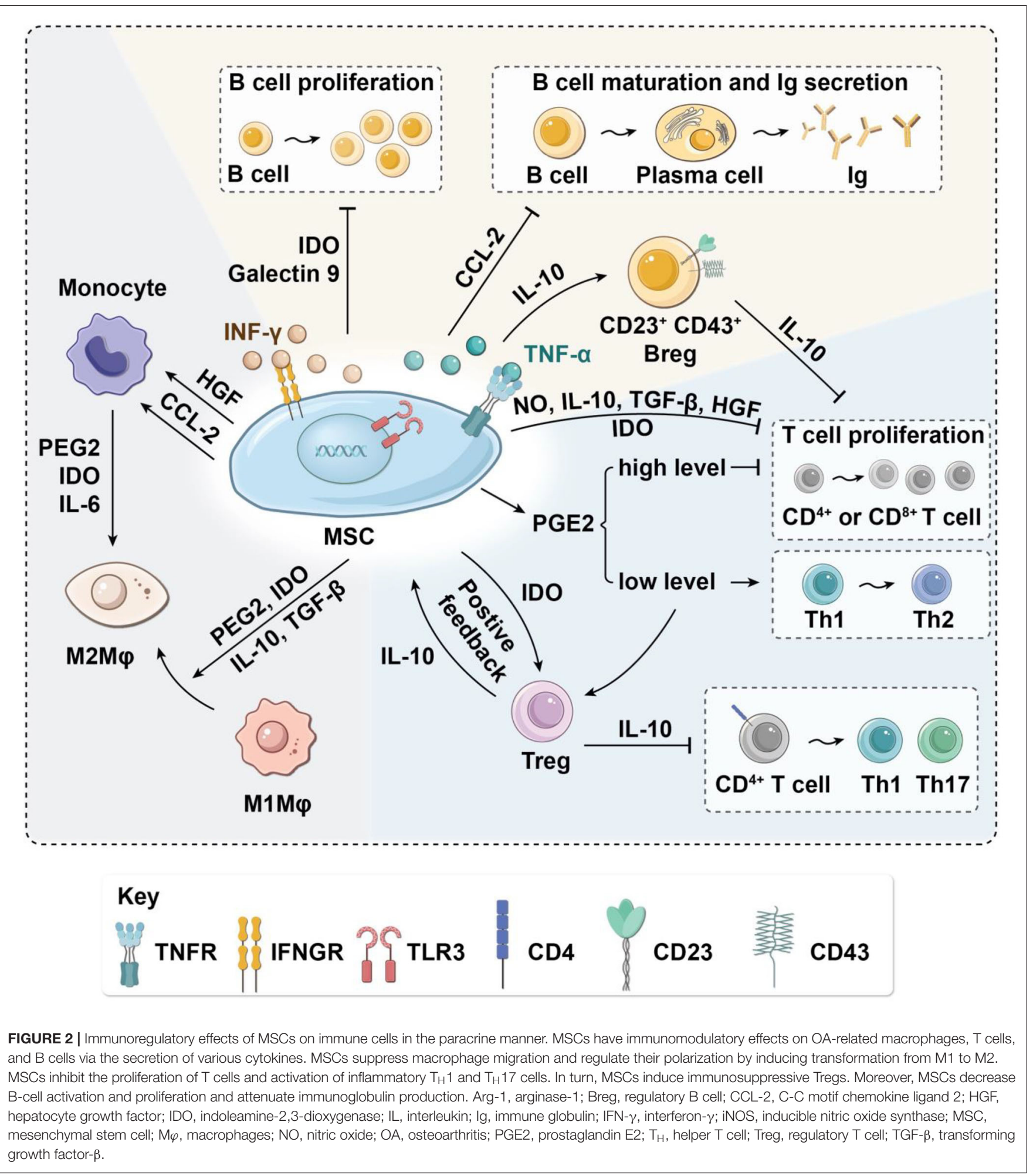

MSCs Modulate T Cell Activation, Differentiation, and Effector Function

Cytokines secreted by MSCs can not only inhibit proliferation and induce apoptosis of $\mathrm{T}$ cells but also suppress the activation of naive $\mathrm{T}$ cells and change the differentiation process of $\mathrm{T}$ cell subsets. Specifically, MSC-secreted cytokines may inhibit proinflammatory T cells and induce Tregs (Kalinski, 2012; LuzCrawford et al., 2013; Baharlou et al., 2019; Jimenez-Puerta et al., 
2020) resulting in decreased production of TNF- $\alpha$ and IL-12 and increased production of IL-10. When the concentration of IL-10 in the microenvironment reaches a certain level, soluble human leukocyte antigen-G5 (HLA-G5) will be secreted, attenuating the activation of $\mathrm{CD}^{+}{ }^{+} \mathrm{T}$ cells to $\mathrm{T}_{\mathrm{H}} 1$ and $\mathrm{T}_{\mathrm{H}} 17$ and inducing Treg production (Selmani et al., 2008), thus forming a positive feedback loop (Figure 2).

Direct contact between MSCs and T cells also plays an important role in the immune regulation of $\mathrm{T}$ cells. The expression of intercellular adhesion molecule- 1 and vascular cell adhesion molecule-1 (VCAM-1) is indispensable for MSCs to exert immunosuppressive effects toward $\mathrm{T}$ cells via increasing the adhesion between MSCs and T cells (Ren et al., 2010; Ma et al., 2017). In addition, some cell-to-cell contact-dependent mechanisms participate in the immunomodulation of $\mathrm{T}$ cells: Fas/FasL signaling pathway activation can induce the apoptosis of inflammatory T cells (Akiyama et al., 2012), Jagged-1/Notch1 signal activation can promote $\mathrm{CD} 4^{+} \mathrm{T}$-cell differentiation into Tregs (Del Papa et al., 2013; Cahill et al., 2015), and programmed death-1/programmed death-1 ligand (PD-1/PD-L1) signaling effectively represses $\mathrm{T}_{\mathrm{H}} 17$ differentiation (Kim et al., 2018). Moreover, direct contact between MSCs and T cells requires HLA-G5, which is responsible for both the contact-dependent and paracrine immunosuppressive functions of MSCs (Figure 3) (Selmani et al., 2008).

In summary, MSCs inhibit the proliferation of T cells and the activation of inflammatory $\mathrm{T}_{\mathrm{H}} 1$ and $\mathrm{T}_{\mathrm{H}} 17$ cells. In turn, MSCs induce immunosuppressive Tregs, thus inhibiting the immune response and attenuating inflammation.

\section{Immunomodulatory Effects of MSCs on B Cells}

Both secreted factors and cell-to-cell contact are needed for MSC modulation of B cells. Che et al. showed that co-culture with MSCs inhibits the phosphorylation of serine/threonine kinase and p38 mitogen-activated protein kinase in B cells (Che et al., 2012), while promoting the phosphorylation of extracellular response kinase 1/2 (ERK1/2) (Tabera et al., 2008). Another recent study showed that co-culture with MSCs significantly enhances the immunomodulatory activity of B cells by upregulating IL-10. Chen et al. found that MSCs can induce a new regulatory B-cell (Breg) population characterized by $\mathrm{CD} 23^{+} \mathrm{CD}_{3} 3^{+}$phenotypes. These $\mathrm{CD} 23^{+} \mathrm{CD} 43^{+}$Breg cells significantly inhibit the secretion of proinflammatory cytokines and the proliferation of $\mathrm{T}$ cells through the IL-10-dependent pathway (Carreras-Planella et al., 2019a; Chen et al., 2019). Rafei et al. found that MSCs inhibit the expression of transcription factor signal transducer and activator of transcription 3 (STAT3) via chemokine $\mathrm{C}-\mathrm{C}$ motif chemokine ligand 2 (CCL2) and then induce paired box 5 (PAX5) protein synthesis to inhibit the secretion of immune globulin in plasma cells (Rafei et al., 2008) (Figure 2). In addition to the paracrine effect, MSCs also play a contact-dependent immunomodulatory role with B cells. Schena et al. found that when activated by a high concentration of IFN- $\gamma$, MSCs can activate the programmed cell death receptor through direct contact and that the PD-1/PD-L1 signaling pathway inhibits the proliferation and maturation of B cells (Figure 3) (Schena et al., 2010).

In conclusion, MSCs can inhibit the proliferation of B cells and the differentiation and maturation of plasma cells and the secretion of antibody, while inducing a new Breg population, and attenuate inflammation in osteoarthritic joints.

\section{MSC-DERIVED EVS AS IMMUNOMODULATORY THERAPEUTICS}

\section{Immunomodulatory Effects of MSC-Derived EVs on Macrophages}

Several studies have shown that MSC-derived EVs can blunt the recruitment of macrophages. For instance, Shen et al. found that MSC-derived EVs express C-C motif chemokine receptor 2, which plays a key role in preventing macrophage accumulation and tissue damage by binding and serving as a decoy to inhibit proinflammatory chemokine CCL2 activity (Shen et al., 2016).

In addition, the therapeutic efficacy of MSC-derived EVs targeting M1/M2 polarization has been studied in various disease models. Zhang et al. found that EVs derived from MSCs have an immunomodulatory effect and can attract M2 macrophages to infiltrate OA cartilage defects and synovium, reduce the infiltration of M1 macrophages, and down-regulate the expression of IL- $1 \beta$ and TNF- $\alpha$, thereby inhibiting the inflammatory response in OA (Zhang S. et al., 2018). In spinal cord injury (SCI) models, the detection of fluorescencelabeled human umbilical cord MSC (hUC-MSC)-derived EVs after intravenous infusion showed that hUC-MSC-derived EVs migrate to the injury site in a manner similar to hUC-MSCs themselves. Macrophages, especially the M2 subtype, are the primary target of EVs at SCI sites (Lankford et al., 2018). Sun et al. further confirmed that hUC-MSC-derived EVs can induce macrophage polarization from M1 to M2 and downregulate the release of inflammatory factors, facilitating the repair of SCI (Sun et al., 2018). In an experimental murine model of bronchopulmonary dysplasia, MSC-derived EVs ameliorated hyperoxia-associated inflammation via modulation of lung macrophage phenotype (Willis et al., 2018). Similar immunoregulatory roles of MSC-derived EVs have been established in inflammatory bowel disease (Schena et al., 2010) and diabetic peripheral neuropathy (Fan et al., 2020).

Several studies have further explored the immunoregulatory mechanism in MSC-derived EVs. Zhao et al. found that mouse bone marrow MSC-derived EVs attenuate myocardial ischemia/reperfusion (I/R) injury in mice via shuttling microRNA-182 (miR-182), which targeted TLR4/nuclear factor $\kappa \mathrm{B} / \mathrm{PI} 3 \mathrm{~K} / \mathrm{Akt}$ signaling, thereby modifying the polarization status of macrophages (Zhao J. et al., 2019). Another study demonstrated that adipose-derived stem cell (ADSC)-derived EVs facilitate the transportation of EV-enriched active STAT3 into macrophages to regulate polarization to the M2 phenotype through the transactivation of Arg-1 (Zhao et al., 2018). A recent study on cutaneous wound healing showed that miR-223, which is contained in MSC-derived EVs, induces the polarization of macrophages by targeting pknox1 (He et al., 2019). 

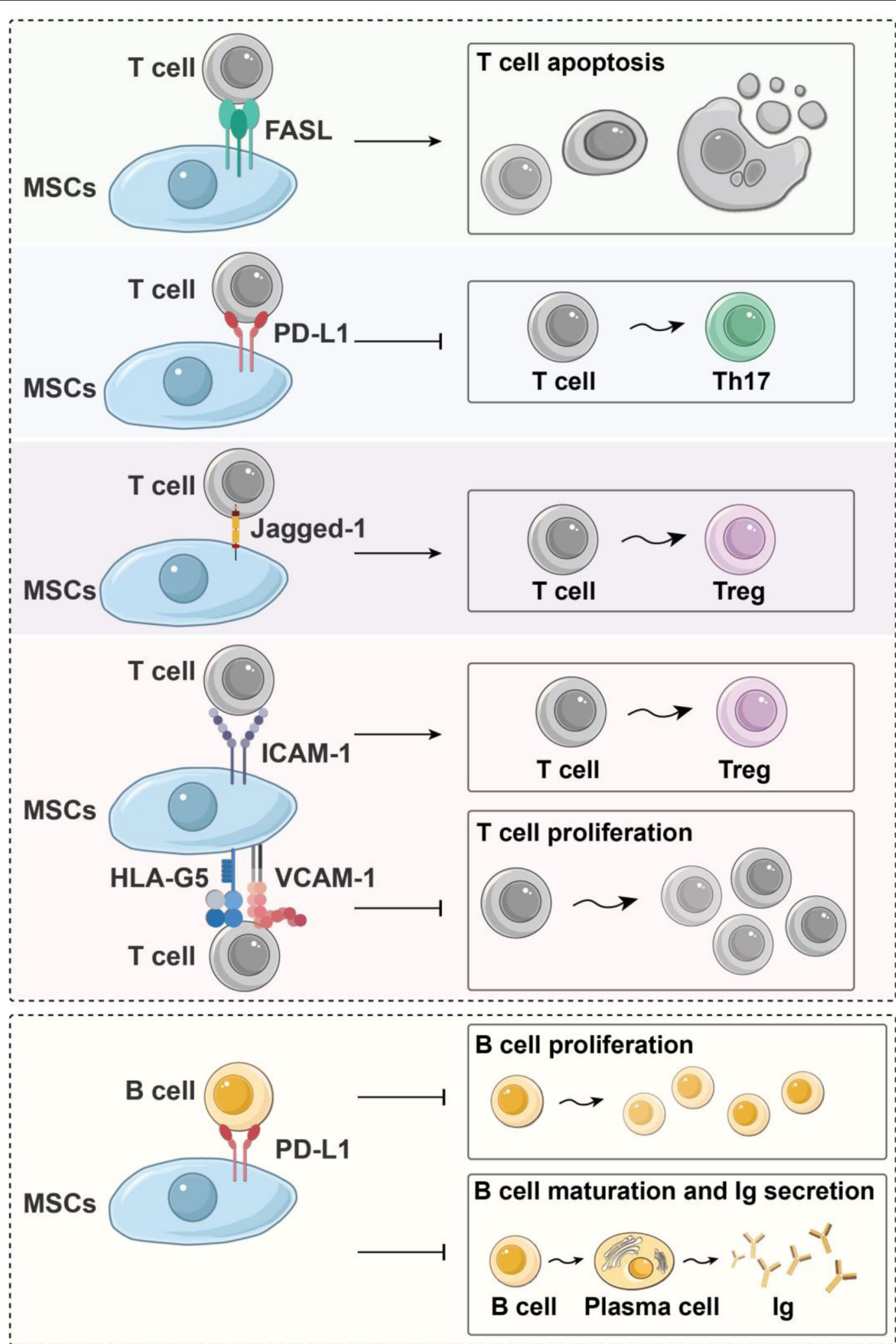

FIGURE 3 | Immunoregulatory effects of MSCs on immune cells in a contact-dependent manner. Fas/FasL signal activation can induce the apoptosis of inflammatory T cells; Jagged-1/Notch-1 signal activation can induce CD4 ${ }^{+}$T cells to differentiate into Tregs, and PD-1/PD-L1 signaling effectively represses $T_{H} 17$ differentiation and 
FIGURE 3 | inhibits the proliferation and maturation of B cells. Moreover, HLA-G5, ICAM-1, and VCAM-1 are needed for MSCs to exert their immunosuppressive effects upon T cells. HLA-G5, human leukocyte antigen-G5; ICAM-1, intercellular adhesion molecule-1; Ig, immune globulin; MSC, mesenchymal stem cells; PD-L1, programmed death-1 ligand; $T_{H}$, helper T cell; Treg, regulatory T cell; VCAM-1, vascular cell adhesion molecule-1.

Preconditioning MSCs with stimulating factors may increase the therapeutic potential of EVs. Ti et al. found that MSC-derived EVs preconditioned with lipopolysaccharide (LPS-EVs) had a more significant regulatory effect on macrophage polarization. The results of microarray analysis showed that the LPSEVs mechanism of immunomodulation is associated with the expression of let-7b, which can impede the TLR4 pathway to regulate macrophage polarization ( $\mathrm{Ti}$ et al., 2015). Song et al. used IL-1 $\beta$ to stimulate hUC-MSCs before administration to septic mice and found that huMSCs transfer miR-146a to macrophages via EVs, thereby promoting the M1-M2 transition. The survival rate of mice in the EV-treated group was decreased after miR-146a inhibition, demonstrating that miR-146a plays a protective role in the treatment of sepsis by MSC-derived EVs (Song et al., 2017). Transfection is another method of MSC modification. Jiang et al. found that miR-30d-5poverexpressing ADSC-derived EVs prevent cerebral injury by inhibiting autophagy-mediated microglial polarization to $\mathrm{M} 1$ via the inhibition of Beclin-1 and autophagy-related gene 5 (ATG5) (Jiang et al., 2018).

These studies indicate that MSC-derived EVs can regulate macrophage polarization in a manner similar to MSCs. Moreover, considering that MSCs have plasticity, the EVs from preconditioned MSCs may possess different characteristics and may obtain better therapeutic effects (Table 1).

\section{Immunomodulatory Effects of MSC-Derived EVs on T Cells}

The effect of MSC-derived EVs on T cells has been described in several in vitro experiments. For example, Chen et al. cocultured peripheral blood mononuclear cells with MSC-derived EVs and found that EVs induce the transformation of $\mathrm{T}_{\mathrm{H}} 1$ cells into $\mathrm{T}_{\mathrm{H}} 2$ cells, reduce the potential of $\mathrm{T}$ cells to differentiate into $\mathrm{T}_{\mathrm{H}} 17$ cells, and increase the content of Tregs (Chen et al., 2016). The regulatory effects of MSC-derived EVs on $\mathrm{T}$ cells have also been confirmed in various disease models. Cosenza et al. assessed the immunosuppressive effects of EVs on $\mathrm{T}$ cells in a delayed-type hypersensitivity model. The results showed that EVs from MSCs inhibited T-cell proliferation and induced Treg populations in a dose-dependent manner, thereby exerting an immunomodulatory effect on inflammatory arthritis (Cosenza et al., 2018). Zhang et al. further demonstrated that MSC-derived EVs induce the differentiation of naive $\mathrm{T}$ cells into Tregs via an APC-mediated pathway in vitro and in vivo (Zhang B. et al., 2018).

Owing to the plasticity of MSCs and the biological characteristics of EVs, EVs from modified MSCs have also been investigated in the field of inflammatory disease therapy. Riazifar et al. evaluated the role of EVs derived from MSCs stimulated by IFN- $\gamma$ (IFN- $\gamma$-EVs) as a treatment in an experimental autoimmune encephalomyelitis mice model (Riazifar et al., 2019). They demonstrated that EVs decreased neuroinflammation and up-regulated the number of Tregs within the spinal region. Furthermore, RNA sequencing showed that IFN- $\gamma$-EVs contained antiinflammatory RNAs and proteins, and inhibition of these RNAs could partially inhibit the potential of EVs to induce Tregs, suggesting potential for EVs as a cell-free therapy for immune-related diseases. Studies have also investigated molding EVs via lentivirus transfection of MSCs. Wei et al. developed an miR-181-overexpressing MSC-EV system that has strong therapeutic effects on myocardial $I / R$ injury. The miRNA-181a mimic was able to interact with the c-Fos mRNA complex and induce Treg differentiation (Wei et al., 2019).

In conclusion, the immunoregulatory effects of MSC-derived EVs on T cells are manifested mainly in the immunosuppression of effector T cells and the induction of Tregs (Table $\mathbf{1}$ ).

\section{Immunomodulatory Effects of MSC-Derived EVs on B Cells}

MSC-derived EVs also play an immunosuppressive role for B cells and can inhibit the terminal differentiation and maturation of plasma cells (Cosenza et al., 2018). In an OA model induced by collagenase, MSC-derived EVs effectively reduce the clinical symptoms of inflammation. However, treatment with IFN- $\gamma$ did not affect the immunosuppressive function of EVs before isolation from MSCs (Cosenza et al., 2018).

A large number of studies have shown that EVs derived from MSCs exert effects through horizontal protein transfer, mRNA, and regulatory microRNA. Based on evidence that miRNA may be transferred to target cells, Khare et al. studied changes in activated B-cell mRNA after culture with bone marrow MSC (BMSC)-derived EVs and found that 186 genes were significantly differentially expressed after culture with EVs. The BMSCderived EVs may inhibit the proliferation and decrease the chemotaxis of B cells by inhibiting the expression of chemokine receptor on B cells (Khare et al., 2018).

However, a recent study showed that the immunomodulatory effect of MSCs on B cells is mediated partially by soluble secreted factors rather than EVs. The authors found that MSC-derived EVs failed to induce naive $\mathrm{B}$ cells or reduce memory $\mathrm{B}$ cells, unliske the MSCs themselves. Furthermore, MSC-derived EVs induced $\mathrm{CD} 24^{+} \mathrm{CD} 38^{+} \mathrm{B}$ cells to a similar extent compared with MSCs, but these B cells did not produce IL-10 and were therefore not considered true Bregs (Carreras-Planella et al., 2019b).

Do MSC-derived EVs have immunosuppressive effects upon B cells? The roles of EVs in MSC-mediated B-cell immunoregulation merit further investigation (Table 1). 
TABLE 1 | Effects of MSC-derived EVs on OA-related immune cells.

\begin{tabular}{|c|c|c|c|c|c|}
\hline Disease model & $\begin{array}{l}\text { Extracellular } \\
\text { vesicle source }\end{array}$ & $\begin{array}{l}\text { Precondition of } \\
\text { MSCs }\end{array}$ & Effects on immune cells & $\begin{array}{l}\text { Defined key } \\
\text { factors }\end{array}$ & References \\
\hline Renal injury & $\begin{array}{l}\text { Mouse } \\
\text { BMSC }\end{array}$ & 1 & $\begin{array}{l}\text { Suppress the recruitment and action of } \\
\text { macrophages }\end{array}$ & CCR2 & Shen et al., 2016 \\
\hline Osteochondral defects & Human ESC-MSC & $\backslash$ & $\begin{array}{l}\text { Induce the infiltration of } \mathrm{M} 2 \mathrm{M} \varphi \text { and } \\
\text { reduce the infiltration of } \mathrm{M} 1 \mathrm{M} \varphi \text { in the } \\
\text { defects }\end{array}$ & 1 & Zhang B. et al., 2018 \\
\hline Spinal cord injury & Human UC-MSC & $\backslash$ & $\begin{array}{l}\text { Induce } \mathrm{M} \varphi \text { polarization from } \mathrm{M} 1 \text { to } \mathrm{M} 2 \\
\text { and down-regulate the release of } \\
\text { inflammatory factors }\end{array}$ & $\backslash$ & Sun et al., 2018 \\
\hline $\begin{array}{l}\text { Experimental } \\
\text { bronchopulmonary dysplasia }\end{array}$ & $\begin{array}{l}\text { Mouse } \\
\text { BMSC }\end{array}$ & $\backslash$ & $\begin{array}{l}\text { Decrease and increase } \mathrm{M} 1 \text { and } \mathrm{M} 2 \mathrm{M} \varphi \\
\text { phenotype markers, respectively }\end{array}$ & $\backslash$ & Willis et al., 2018 \\
\hline IBD & $\begin{array}{l}\text { Human } \\
\text { BMSC }\end{array}$ & 1 & $\begin{array}{l}\text { Metallothionein- } 2 \text { acts as a critical } \\
\text { negative regulator of the inflammatory } \\
\text { response in } \mathrm{M} \varphi \mathrm{s} \text {. }\end{array}$ & Metallothionein-2 & Liu et al., 2019 \\
\hline DPN & $\begin{array}{l}\text { Mouse } \\
\text { BMSC }\end{array}$ & $\backslash$ & $\begin{array}{l}\text { Decrease and increase } \mathrm{M} 1 \text { and } \mathrm{M} 2 \mathrm{M} \varphi \\
\text { phenotype markers, respectively }\end{array}$ & $\begin{array}{l}\text { miR-17, miR-23a, } \\
\text { miR-125b }\end{array}$ & Fan et al., 2020 \\
\hline Myocardial I/R injury & $\begin{array}{l}\text { Mouse } \\
\text { BMSC }\end{array}$ & 1 & $\begin{array}{l}\text { Mediate macrophage polarization from } \\
\text { M1 to M2 }\end{array}$ & miR-182 & Zhao J. et al., 2019 \\
\hline Obesity-induced inflammation & $\begin{array}{l}\text { Mouse } \\
\text { ADSC }\end{array}$ & $\backslash$ & Induce M2 M $\varphi$ polarization & Activated STAT3 & Zhao et al., 2018 \\
\hline Skin defect & $\begin{array}{l}\text { Human jaw } \\
\text { BMSC }\end{array}$ & $\backslash$ & Induce $\mathrm{M} 2 \mathrm{M} \varphi$ polarization & miR-223 & He et al., 2019 \\
\hline Diabetic cutaneous wounds & $\begin{array}{l}\text { Human } \\
\text { UC-MSC }\end{array}$ & Stimulated by LPS & Induce M2 M $\varphi$ polarization & let-7b & Ti et al., 2015 \\
\hline Sepsis & $\begin{array}{l}\text { Human } \\
\text { UC-MSC }\end{array}$ & $\begin{array}{l}\text { Stimulated by } \\
\text { IL-1 } 1 \beta\end{array}$ & Induce M2 M $\varphi$ polarization & miR-146a & Song et al., 2017 \\
\hline Middle cerebral artery occlusion & $\begin{array}{l}\text { Rat } \\
\text { ADSC }\end{array}$ & $\begin{array}{l}\text { Transfection of } \\
\text { miR-30d-5p mimic }\end{array}$ & $\begin{array}{l}\text { Transform microglial/macrophage } \\
\text { polarization from } \mathrm{M} 1 \text { to } \mathrm{M} 2\end{array}$ & miR-30d-5p & Jiang et al., 2018 \\
\hline$\backslash$ & $\begin{array}{l}\text { Human } \\
\text { BMSC }\end{array}$ & $\backslash$ & $\begin{array}{l}\text { Induce the transformation of } T_{H} 1 \text { cells } \\
\text { into } T_{H} 2 \text { cells, reduce the potential of } T \\
\text { cells to differentiate into } T_{H} 17 \text { cells and } \\
\text { increase the content of Tregs }\end{array}$ & $\backslash$ & Chen et al., 2016 \\
\hline Arthritis (DTH or CIA induced) & $\begin{array}{l}\text { Mouse } \\
\text { BMSC }\end{array}$ & $\backslash$ & $\begin{array}{l}\text { Inhibit T-cell proliferation through Treg } \\
\text { induction. } \\
\text { Suppress plasma cell differentiation and } \\
\text { induce Bregs }\end{array}$ & 1 & Cosenza et al., 2018 \\
\hline GVHD & $\begin{array}{l}\text { Human } \\
\text { ESC-MSC }\end{array}$ & $\backslash$ & $\begin{array}{l}\text { Induce the differentiation of naive } T \text { cells } \\
\text { into Tregs }\end{array}$ & $\backslash$ & Zhang B. et al., 2018 \\
\hline EAE & $\begin{array}{l}\text { Human } \\
\text { BMSC }\end{array}$ & $\begin{array}{l}\text { Stimulated by } \\
\text { IFN- } \gamma\end{array}$ & $\begin{array}{l}\text { Suppress T Cell Proliferation and } \\
\text { up-regulate the number of Tregs within } \\
\text { the spinal }\end{array}$ & $\begin{array}{l}\text { Aggrecan, periostin, } \\
\text { HAPLN1 }\end{array}$ & Riazifar et al., 2019 \\
\hline Myocardial I/R injury & $\begin{array}{l}\text { Human } \\
\text { UC-MSC }\end{array}$ & $\begin{array}{l}\text { Transfection of } \\
\text { miR-181 mimic }\end{array}$ & Induce the differentiation of Tregs & miR-181 & Wei et al., 2019 \\
\hline$\backslash$ & $\begin{array}{l}\text { Human } \\
\text { BMSC }\end{array}$ & $\backslash$ & $\begin{array}{l}\text { Inhibit the proliferation of B cells and } \\
\text { decrease the chemotaxis of B cells }\end{array}$ & CXCL8, MZB1 & Khare et al., 2018 \\
\hline
\end{tabular}

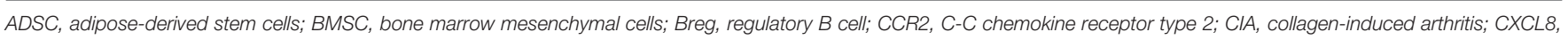

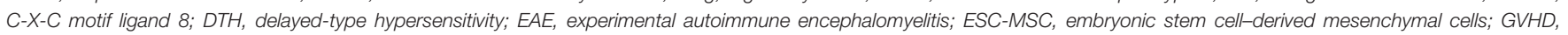

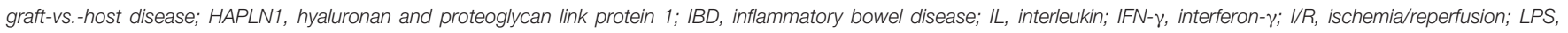

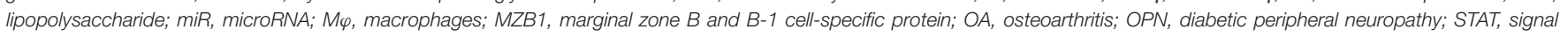
transducer and activator of transcription; $T_{H}$, helper T cell; Treg, regulatory T cell; UC-MSC, umbilical cord-derived mesenchymal cells.

\section{SUSTAINED DELIVERY OF EVS}

One challenge in the application of sustained EV delivery systems is the difficulty of producing EVs in large quantities and with high purity (Yamashita et al., 2018). The typical yield of EVs isolated from $1 \mathrm{~mL}$ of medium may be $<1 \mu \mathrm{g}$ EV protein, whereas the effective dose of EVs in mouse models typically ranges from 10 to $100 \mu \mathrm{g}$ of protein. Humans are expected to require larger therapeutic doses (Willis et al., 2017). The endocytic pathway of target cells is the main route by which EVs exert their biological effects (Mulcahy et al., 2014). However, studies have shown that, regardless of their source and whether they are administered 
through direct intravenous injection, subcutaneous injection or any other direct delivery routes, EVs will be quickly cleared from blood circulation and discharged from the body (Smyth et al., 2015; Charoenviriyakul et al., 2017). Therefore, prolonging the half-life of EVs to maximize their local therapeutic effects remains a major challenge.

To overcome this limitation, biomaterials may be utilized in EV encapsulation strategies to deliver EVs in a sustainedrelease manner. Hydrogels are three-dimensional cross-linked hydrophilic polymers with biological media that swell in water but do not dissolve (Narayanaswamy and Torchilin, 2019). Because hydrogels are biodegradable, biocompatible, and nontoxic, they have received great attention in various fields. Hydrogels can serve as biological drug delivery systems, cell encapsulation matrices, or scaffolds in regenerative medicine (Oliva et al., 2017; Mahdavinia et al., 2018). Hydrogel is considered to be an excellent carrier for EVs and may be capable of effectively delivering EVs to damaged tissues and prolonging their effects (Riau et al., 2019).

Liu et al. developed a photoinduced imine-crosslinking hydrogel glue to load-induced pluripotent stem cell-derived EVs for repairing knee articular cartilage defects, effectively prolonging the activity of stem cell-derived EVs promoting the repair of cartilage defects (Liu et al., 2017). Zhang et al. isolated EVs from human placenta-derived MSCs and combined EVs with chitosan hydrogel to form hydrogel-incorporated EVs (CSEVs). They evaluated the effects of CS-EVs in endothelial cells using a murine hindlimb ischemia model and found that chitosan hydrogel strongly enhanced the retention of EVs at the target site. CS-EVs had advantageous functions compared with EVs alone, including enhancing angiogenesis, suppressing apoptosis of muscle cells, and attenuating fibrosis (Zhang K. et al., 2018). Henriques-Antunes et al. exploited a light triggerable hyaluronic acid hydrogel for the remote release control of EVs, which is more efficient in regulating EVs release according to the tissue healing dynamics in diabetic chronic wounds. Moreover, this hydrogel can provide antimicrobial activity by incorporating autolytic enzymes such as collagenases and antimicrobial peptides in order to avoid recurrent infection (Henriques-Antunes et al., 2019). Given that the mesh size of the ECM is usually smaller than the size of EVs, understanding how EVs are dispersed is critical to developing these cell-free therapies and stopping disease progression. Recently, Lenzini et al. revealed the diffusion and transport process of EVs in dense ECM by using engineered hydrogel. They confirmed that matrix stress relaxation is a key factor for EVs to overcome the confinement and that water infiltration also plays an essential role in EV deformation and navigation in ECM. These findings bring us closer to designing effective drug delivery systems (Lenzini et al., 2020).

\section{PERSPECTIVE}

The current viewpoint of OA is evolving from a simple mechanical joint injury toward a complex organ disease that involves biomechanics, inflammation, and the immune system. Macrophages, T cells, and B cells are the three main immune cells that control the inflammatory processes and immune response in OA. They form a complex network regulation system through coordination and antagonism. For example, $\mathrm{T}_{\mathrm{H}} 2$ cells can induce macrophage polarization via cytokines, yet the M2 polarization of macrophages might be involved in the induction of Tregs (Murray, 2017; Phan et al., 2017). Each of these processes overlaps and is also related to the local microenvironment, including trauma, inflammation, and cartilage remodeling. Fully understanding the complex inflammatory network system in OA will facilitate more effective and systematic treatment (Figure 1).

Currently, several studies have demonstrated the immunomodulatory effects of MSCs/EVs during OA, but there is still a lack of hard evidence of key factors and related mechanisms. Therefore, we also discussed the immunomodulatory effect of MSCs/EVs in some similar disease models based on chronic degenerative diseases with chronic inflammation hereinabove. We speculate that MSCs/EVs have similar immunomodulatory mechanisms in OA, and these roles need to be further investigated by future research in OA models.

As we have seen, MSCs have been widely used in regenerative therapy and immunotherapy owing to their anti-inflammatory and immunomodulatory effects (Prockop and Oh, 2012). The role of MSCs is to adjust the balance between inflammation and tissue reconstruction to provide the damaged tissue with a relatively stable environment, which is beneficial for tissue repair (Shi et al., 2018). However, direct MSC transplantation has several critical limitations to overcome: (1) the procurement of some stem cells, such as embryonic stem cells, is still controversial; (2) it is difficult to predict the lasting capacity for cell behavior and cell-cell interactions because of aging; (3) the survival rate associated with stem cell transplantation is low; (4) there is immune rejection in some patients; (5) the procedures are typically expensive and have a high risk of infection (Jiang and $\mathrm{Xu}, 2020$ ). Moreover, as has been noted, MSCs are sensitive to certain microenvironment or inflammatory milieu and undergo specific behavioral modification. The plasticity of MSCs may have a negative impact on direct MSC transplantation. For example, MSCs can switch to MSC1, when induced by exposure to a low level of TLR2/4 ligands in vivo, and can then take effect in augmenting the inflammatory response (Tomchuck et al., 2008; Lei et al., 2011).

Therefore, more and more researchers have tended to test the secretory products of MSCs, including MSC-derived EVs in animal models of OA, rather than direct transplanting MSCs themselves. EVs derived from MSCs have been proven to reproduce some benefits of MSC-mediated immunosuppression (Mianehsaz et al., 2019). They can transfer miRNA or other bioactive substances such as cytokines, growth factors, and metabolites to target cells, thus playing the role of immune regulators. Being cell-free particles, EVs can avoid any chance of cell modification, and this guaranteed the stability of soluble bioactive factor types and abundance applied to the degenerative joint. Further knowledge regarding the mechanisms of action for MSCs and EVs in OA will enable individual assessments of the severity of the articular condition. Based on the plasticity of MSCs, it may be possible to obtain EVs with different characteristics prior to application to develop personalized 
treatments and increase therapeutic efficacy (Ti et al., 2015; Song et al., 2017; Jiang et al., 2018; Riazifar et al., 2019). However, EV-based therapy has some disadvantages: First, MSCs have numerous contact effects and numerous paracrine effects including EVs; therefore, EVs can reproduce the positive function of MSCs partially, but not all of them. Second, the major drawback of EVs is their rapid clearance, and sustained local delivery of EVs is therefore important (Smyth et al., 2015; Charoenviriyakul et al., 2017). It is also important to determine how to prepare EVs quickly, cheaply, and efficiently. Moreover, as described in Immunomodulatory Effects of MSCDerived EVs on B Cells, a recent study different from previous studies reported no or low functional effects of EVs on B cells (Carreras-Planella et al., 2019b). This discrepancy may be due to a variety of factors, including MSC sources, isolation methods, culture conditions, and/or the use of repeated freeze-thawed EVs. Another possibility is that EVs play a small role in MSC-mediated B-cell immunoregulation, which need further investigation; if that is the case, the appropriate treatment (cell or cell-free) should be selected according to different targeted immune cells.

To sum up, EVs avoid some of the inherent risks of MSC therapies and hold great promise in a range of applications. However, there are still many uncertain aspects of the

\section{REFERENCES}

Abumaree, M. H., Al Jumah, M. A., Kalionis, B., Jawdat, D., Al Khaldi, A., Abomaray, F. M., et al. (2013). Human placental mesenchymal stem cells (pMSCs) play a role as immune suppressive cells by shifting macrophage differentiation from inflammatory M1 to anti-inflammatory M2 macrophages. Stem Cell Rev. Rep. 9, 620-641. doi: 10.1007/s12015-013-9455-2

Akiyama, K., Chen, C., Wang, D., Xu, X., Qu, C., Yamaza, T., et al. (2012). Mesenchymal-stem-cell-induced immunoregulation involves FAS-ligand-/FAS-mediated T cell apoptosis. Cell Stem Cell 10, 544-555. doi: 10.1016/j.stem.2012.03.007

Aspden, R. M., and Saunders, F. R. (2019). Osteoarthritis as an organ disease: from the cradle to the grave. Eur Cells Mater. 37, 74-87. doi: 10.22203/eCM.v037a06

Ayala-Cuellar, A. P., Kang, J. H., Jeung, E. B., and Choi, K. C. (2019). Roles of mesenchymal stem cells in tissue regeneration and immunomodulation. Biomol. Ther. 27, 25-33. doi: 10.4062/biomolther.2017.260

Baharlou, R., Rashidi, N., Ahmadi-Vasmehjani, A., Khoubyari, M., Sheikh, M., and Erfanian, S. (2019). Immunomodulatory effects of human adipose tissue-derived mesenchymal stem cells on $\mathrm{T}$ cell subsets in patients with rheumatoid arthritis. Iran. J. Allergy Asthma Immunol. 18, 114-119. doi: 10.18502/ijaai.v18i1.637

Barry, F., and Murphy, M. (2013). Mesenchymal stem cells in joint disease and repair. Nat. Rev. Rheumatol 9, 584-594. doi: 10.1038/nrrheum.2013.109

Behm, C., Blufstein, A., Gahn, J., Nemec, M., Moritz, A., Rausch-Fan, X., et al. (2020). Cytokines differently define the immunomodulation of mesenchymal stem cells from the periodontal ligament. Cells 9:1222. doi: 10.3390/cells9051222

Blom, A. B., van Lent, P. L., Libregts, S., Holthuysen, A. E., van der Kraan, P. M., van Rooijen, N., et al. (2007). Crucial role of macrophages in matrix metalloproteinase-mediated cartilage destruction during experimental osteoarthritis: involvement of matrix metalloproteinase 3. Arthritis Rheum. 56, 147-157. doi: 10.1002/art.22337

Bommireddy, R., and Doetschman, T. (2007). TGFbetal and Treg cells: alliance for tolerance. Trends Mol. Med. 13, 492-501. doi: 10.1016/j.molmed.2007.08.005

Bui, T. M., Mascarenhas, L. A., and Sumagin, R. (2018). Extracellular vesicles regulate immune responses and cellular function in intestinal inflammation and repair. Tissue Barriers 6, e1431038. doi: 10.1080/21688370.2018.1431038 interactions between MSCs/MSC-derived EVs and immune cells involved in $\mathrm{OA}$, and future studies should further explore and optimize the role of EVs in immunoregulation and enable the efficient application of EVs in clinical therapy.

\section{AUTHOR CONTRIBUTIONS}

$\mathrm{XW}$ and QY initiated the project and made suggestions and revised the article. XZ, YZ, XS, and YX searched the database, wrote, and finalized the manuscript. All authors reviewed and commented on the entire manuscript.

\section{FUNDING}

This work was supported by National Key Research and Development Program of China (2020YFC1107402 and 2019YFC110005), National Natural Science Foundation of China (31300798, 81871782, 51973226, and 31900968), Youth Innovation Promotion Association CAS (No. 2019031), Tianjin Science Fund for Distinguished Young Scholars (18JCJQJC47900), and Research Foundation of the Tianjin Health Bureau (16KG114).

Burr, S. P., Dazzi, F., and Garden, O. A. (2013). Mesenchymal stromal cells and regulatory T cells: the Yin and Yang of peripheral tolerance? Immunol. Cell Biol. 91, 12-18. doi: 10.1038/icb.2012.60

Cahill, E. F., Tobin, L. M., Carty, F., Mahon, B. P., and English, K. (2015). Jagged-1 is required for the expansion of CD4(+) CD25(+) FoxP3(+) regulatory T cells and tolerogenic dendritic cells by murine mesenchymal stromal cells. Stem Cell Res. Ther. 6:19. doi: 10.1186/s13287-015-0021-5

Carreras-Planella, L., Monguió-Tortajada, M., Borràs, F., and Franquesa, M. (2019a). Corrigendum: immunomodulatory effect of MSC on B cells is independent of secreted extracellular vesicles. Front. Immunol. 10:2413. doi: 10.3389/fimmu.2019.02413

Carreras-Planella, L., Monguió-Tortajada, M., Borràs, F., and Franquesa, M. (2019b). Immunomodulatory effect of MSC on B cells is independent of secreted extracellular vesicles. Front. Immunol. 10:1288. doi: 10.3389/fimmu.2019.01288

Charoenviriyakul, C., Takahashi, Y., Morishita, M., Matsumoto, A., Nishikawa, M., and Takakura, Y. (2017). Cell type-specific and common characteristics of exosomes derived from mouse cell lines: yield, physicochemical properties, and pharmacokinetics. Eur. J. Pharm. Sci. 96, 316-322. doi: 10.1016/j.ejps.2016.10.009

Che, N., Li, X., Zhou, S. L., Liu, R., Shi, D. Y., Lu, L. W., et al. (2012). Umbilical cord mesenchymal stem cells suppress B-cell proliferation and differentiation. Cell. Immunol. 274, 46-53. doi: 10.1016/j.cellimm.2012.02.004

Chen, W., Huang, Y., Han, J., Yu, L., Li, Y., Lu, Z., et al. (2016). Immunomodulatory effects of mesenchymal stromal cells-derived exosome. Immunol. Res. 64, 831-840. doi: 10.1007/s12026-016-8798-6

Chen, X., Cai, C., Xu, D., Liu, Q., Zheng, S., Liu, L., et al. (2019). Human mesenchymal stem cell-treated regulatory CD23(+)CD43(+) B cells alleviate intestinal inflammation. Theranostics 9, 4633-4647. doi: 10.7150/thno. 32260

Chen, Y., Jiang, W., Yong, H., He, M., Yang, Y., Deng, Z., et al. (2020). Macrophages in osteoarthritis: pathophysiology and therapeutics. Am. J. Transl. Res. 12, 261-268.

Cho, D. I., Kim, M. R., Jeong, H. Y., Jeong, H. C., Jeong, M. H., Yoon, S. H., et al. (2014). Mesenchymal stem cells reciprocally regulate the M1/M2 balance in mouse bone marrow-derived macrophages. Exp. Mol. Med. 46:e70. doi: $10.1038 / \mathrm{emm} .2013 .135$ 
Chow, Y. Y., and Chin, K. Y. (2020). The Role of Inflammation in the Pathogenesis of Osteoarthritis. Mediators Inflamm. 2020:8293921. doi: $10.1155 / 2020 / 8293921$

Cosenza, S., Toupet, K., Maumus, M., Luz-Crawford, P., Blanc-Brude, O., Jorgensen, C., et al. (2018). Mesenchymal stem cells-derived exosomes are more immunosuppressive than microparticles in inflammatory arthritis. Theranostics 8, 1399-1410. doi: 10.7150/thno.21072

de Castro, L. L., Lopes-Pacheco, M., Weiss, D. J., Cruz, F. F., and Rocco, P. R. M. (2019). Current understanding of the immunosuppressive properties of mesenchymal stromal cells. J. Mol. Med. 97, 605-618. doi: 10.1007/s00109-019-01776-y

de Lange-Brokaar, B. J. E., Ioan-Facsinay, A., van Osch, G. J. V. M., Zuurmond, A. M., Schoones, J., Toes, R. E., et al. (2012). Synovial inflammation, immune cells and their cytokines in osteoarthritis: a review. Osteoarthr. Cartilage 20, 1484-1499. doi: 10.1016/j.joca.2012.08.027

Del Papa, B., Sportoletti, P., Cecchini, D., Rosati, E., Balucani, C., Baldoni, S., et al. (2013). Notch1 modulates mesenchymal stem cells mediated regulatory T-cell induction. Eur. J. Immunol. 43, 182-187. doi: 10.1002/eji.201242643

Fahy, N., de Vries-van Melle, M. L., Lehmann, J., Wei, W., Grotenhuis, N., Farrell, E., et al. (2014). Human osteoarthritic synovium impacts chondrogenic differentiation of mesenchymal stem cells via macrophage polarisation state. Osteoarthr. Cartilage 22, 1167-1175. doi: 10.1016/j.joca.2014.05.021

Fan, B., Li, C., Szalad, A., Wang, L., Pan, W., Zhang, R., et al. (2020). Mesenchymal stromal cell-derived exosomes ameliorate peripheral neuropathy in a mouse model of diabetes. Diabetologia 63, 431-443. doi: 10.1007/s00125-019-05043-0

Faulknor, R. A., Olekson, M. A., Ekwueme, E. C., Krzyszczyk, P., Freeman, J. W., and Berthiaume, F. (2017). Hypoxia impairs mesenchymal stromal cell-induced macrophage M1 to M2 transition. Technology 5, 81-86. doi: $10.1142 /$ S2339547817500042

Fernandes, T. L., Gomoll, A. H., Lattermann, C., Hernandez, A. J., Bueno, D. F., and Amano, M. T. (2020). Macrophage: a potential target on cartilage regeneration. Front. Immunol. 11:111. doi: 10.3389/fimmu.2020. 00111

Fernandez-Pernas, P., Barrachina, L., Marquina, M., Rodellar, C., Arufe, M. C., and Costa, C. (2020). Mesenchymal stromal cells for articular cartilage repair: preclinical studies. Eur. Cell. Mater 40, 88-114. doi: 10.22203/eCM. v040a06

Fichadiya, A., Bertram, K. L., Ren, G., Yates, R. M., and Krawetz, R. J. (2016). Characterizing heterogeneity in the response of synovial mesenchymal progenitor cells to synovial macrophages in normal individuals and patients with osteoarthritis. J. Inflamm. 13:12. doi: 10.1186/s12950-016-0120-9

Glennie, S., Soeiro, I., Dyson, P. J., Lam, E. W., and Dazzi, F. (2005). Bone marrow mesenchymal stem cells induce division arrest anergy of activated T cells. Blood 105, 2821-2827. doi: 10.1182/blood-2004-09-3696

Guillamat-Prats, R., Camprubi-Rimblas, M., Bringue, J., Tantinya, N., and Artigas, A. (2017). Cell therapy for the treatment of sepsis and acute respiratory distress syndrome. Ann. Transl. Med. 5:446. doi: 10.21037/atm.2017.08.28

Haynes, M. K., Hume, E. L., and Smith, J. B. (2002). Phenotypic characterization of inflammatory cells from osteoarthritic synovium and synovial fluids. Clin. Immunol. 105, 315-325. doi: 10.1006/clim.2002.5283

He, X., Dong, Z., Cao, Y., Wang, H., Liu, S., Liao, L., et al. (2019). MSC-derived exosome promotes $\mathrm{m} 2$ polarization and enhances cutaneous wound healing. Stem Cells Int. 2019:7132708. doi: 10.1155/2019/7132708

Henriques-Antunes, H., Cardoso, M. S. R., Zonari, A., Correia, J., Leal, E. C., Jiménez-Balsa, A., et al. (2019). The kinetics of small extracellular vesicle delivery impacts skin tissue regeneration. ACS Nano 13, 8694-8707. doi: 10.1021/acsnano.9b00376

Hori, S., Nomura, T., and Sakaguchi, S. (2003). Control of regulatory T cell development by the transcription factor Foxp3. Science 299, 1057-1061. doi: $10.1126 /$ science. 1079490

Hsieh, J. L., Shiau, A. L., Lee, C. H., Yang, S. J., Lee, B. O., Jou, I. M., et al. (2013). CD8+ T cell-induced expression of tissue inhibitor of metalloproteinses-1 exacerbated osteoarthritis. Int. J. Mol. Sci. 14, 19951-19970. doi: 10.3390/ijms141019951

Hu, T., Xu, H., Wang, C., Qin, H., and An, Z. (2018). Magnesium enhances the chondrogenic differentiation of mesenchymal stem cells by inhibiting activated macrophage-induced inflammation. Sci. Rep. 8:3406. doi: $10.1038 /$ s41598-018-21783-2
Huang, Z. Y., and Kraus, V. B. (2016). Does lipopolysaccharide-mediated inflammation have a role in OA? Nat. Rev. Rheumatol. 12, 123-129. doi: $10.1038 /$ nrrheum.2015.158

Hunter, D. J., and Bierma-Zeinstra, S. (2019). Osteoarthritis. Lancet 393, 1745-1759. doi: 10.1016/S0140-6736(19)30417-9

Hussein, M. R., Fathi, N. A., El-Din, A. M., Hassan, H. I., Abdullah, F., Al-Hakeem, E., et al. (2008). Alterations of the CD4(+), CD8 (+) T cell subsets, interleukins1beta, IL-10, IL-17, tumor necrosis factor-alpha and soluble intercellular adhesion molecule-1 in rheumatoid arthritis and osteoarthritis: preliminary observations. Pathol. Oncol. Res. 14, 321-328. doi: 10.1007/s12253-008-9016-1

Jiang, M., Wang, H., Jin, M., Yang, X., Ji, H., Jiang, Y., et al. (2018). Exosomes from MiR-30d-5p-ADSCs reverse acute ischemic stroke-induced, autophagymediated brain injury by promoting M2 microglial/macrophage polarization. Cell. Physiol. Biochem. 47, 864-878. doi: 10.1159/000490078

Jiang, W., and Xu, J. Y. (2020). Immune modulation by mesenchymal stem cells. Cell Prolif. 53:e12712. doi: 10.1111/cpr.12712

Jimenez-Puerta, G. J., Marchal, J. A., Lopez-Ruiz, E., and Galvez-Martin, P. (2020). Role of mesenchymal stromal cells as therapeutic agents: potential mechanisms of action and implications in their clinical use. J. Clin. Med. 9:445. doi: $10.3390 / \mathrm{jcm} 9020445$

Kalinski, P. (2012). Regulation of immune responses by prostaglandin E2. J. Immunol. 188, 21-28. doi: 10.4049/jimmunol.1101029

Kalluri, R., and LeBleu, V. S. (2020). The biology, function, and biomedical applications of exosomes. Science 367:eaau6977. doi: 10.1126/science.aau6977

Kawahara, K., Hohjoh, H., Inazumi, T., Tsuchiya, S., and Sugimoto, Y. (2015). Prostaglandin E2-induced inflammation: Relevance of prostaglandin E receptors. Biochim. Biophys. Acta 1851, 414-421. doi: 10.1016/j.bbalip.2014.07.008

Khare, D., Or, R., Resnick, I., Barkatz, C., Almogi-Hazan, O., and Avni, B. (2018). Mesenchymal stromal cell-derived exosomes affect mRNA expression and function of B-lymphocytes. Front. Immunol. 9:3053. doi: 10.3389/fimmu.2018.03053

Kim, J. Y., Park, M., Kim, Y. H., Ryu, K. H., Lee, K. H., Cho, K. A., et al. (2018). Tonsil-derived mesenchymal stem cells (T-MSCs) prevent Th17-mediated autoimmune response via regulation of the programmed death-1/programmed death ligand-1 (PD-1/PD-L1) pathway. J. Tissue Eng. Regen. Med. 12, e1022e1033. doi: $10.1002 /$ term. 2423

Kyurkchiev, D., Bochev, I., Ivanova-Todorova, E., Mourdjeva, M., Oreshkova, T., Belemezova, K., et al. (2014). Secretion of immunoregulatory cytokines by mesenchymal stem cells. World J. Stem Cells 6, 552-570. doi: $10.4252 /$ wjsc.v6.i5.552

Labinsky, H., Panipinto, P. M., Ly, K. A., Khuat, D. K., Madarampalli, B., Mahajan, V., et al. (2020). Multiparameter analysis identifies heterogeneity in knee osteoarthritis synovial responses. Arthritis Rheumatol. 72, 598-608. doi: $10.1002 /$ art. 41161

Lankford, K. L., Arroyo, E. J., Nazimek, K., Bryniarski, K., Askenase, P. W., and Kocsis, J. D. (2018). Intravenously delivered mesenchymal stem cell-derived exosomes target M2-type macrophages in the injured spinal cord. PLoS ONE 13:e0190358. doi: 10.1371/journal.pone.0190358

Lee, S., Zhang, Q., Karabucak, B., and Le, A. (2016). DPSCs from inflamed pulp modulate macrophage function via the TNF- $\alpha /$ IDO axis. J. Dent. Res. 95, 1274-1281. doi: 10.1177/0022034516657817

Lei, J. X., Wang, Z., Hui, D. Y., Yu, W. H., Zhou, D. H., Xia, W. J., et al. (2011). Ligation of TLR2 and TLR4 on murine bone marrow-derived mesenchymal stem cells triggers differential effects on their immunosuppressive activity. Cell. Immunol. 271, 147-156. doi: 10.1016/j.cellimm.2011.06.014

Lenzini, S., Bargi, R., Chung, G., and Shin, J. W. (2020). Matrix mechanics and water permeation regulate extracellular vesicle transport. Nat. Nanotechnol. 15, 217-223. doi: 10.1038/s41565-020-0636-2

Li, Y. S., Luo, W., Zhu, S. A., and Lei, G. H. (2017). T cells in osteoarthritis: alterations and beyond. Front. Immunol. 8:356. doi: 10.3389/fimmu.2017.00356

Lin, L. Y., and Du, L. M. (2018). The role of secreted factors in stem cells-mediated immune regulation. Cell. Immunol. 326, 24-32. doi: 10.1016/j.cellimm.2017.07.010

Liu, H., Liang, Z., Wang, F., Zhou, C., Zheng, X., Hu, T., et al. (2019). Exosomes from mesenchymal stromal cells reduce murine colonic inflammation via a macrophage-dependent mechanism. JCI Insight 4:e131273. doi: $10.1172 /$ jci.insight. 131273 
Liu, X. L., Yang, Y. L., Li, Y., Niu, X., Zhao, B. Z., Wang, Y., et al. (2017). Integration of stem cell-derived exosomes with in situ hydrogel glue as a promising tissue patch for articular cartilage regeneration. Nanoscale 9, 4430-4438. doi: $10.1039 / C 7 N R 00352 \mathrm{H}$

Liu, Y. L., Zhang, Y. J., Zheng, X. F., Zhang, X. S., Wang, H. M., Li, Q., et al. (2016). Gene silencing of indoleamine 2,3-dioxygenase 2 in melanoma cells induces apoptosis through the suppression of NAD plus and inhibits in vivo tumor growth. Oncotarget 7, 32329-32340. doi: 10.18632/oncotarget.8617

Loeser, R. F. (2013). Aging processes and the development of osteoarthritis. Curr. Opin. Rheumatol. 25, 108-113. doi: 10.1097/BOR.0b013e32835a9428

Luz-Crawford, P., Kurte, M., Bravo-Alegria, J., Contreras, R., NovaLamperti, E., Tejedor, G., et al. (2013). Mesenchymal stem cells generate a CD4+CD25+Foxp3+ regulatory $\mathrm{T}$ cell population during the differentiation process of Th1 and Th17 cells. Stem Cell Res. Ther. 4, 65. doi: 10.1186/scrt216

Ma, S., Chen, X., Wang, L., Wei, Y., Ni, Y., Chu, Y., et al. (2017). Repairing effects of ICAM-1-expressing mesenchymal stem cells in mice with autoimmune thyroiditis. Exp. Ther. Med. 13, 1295-1302. doi: 10.3892/etm.2017.4131

Mahdavinia, G. R., Soleymani, M., Etemadi, H., Sabzi, M., and Atlasi, Z. (2018). Model protein BSA adsorption onto novel magnetic chitosan/PVA/laponite RD hydrogel nanocomposite beads. Int. J. Biol. Macromol. 107, 719-729. doi: 10.1016/j.ijbiomac.2017.09.042

Mianehsaz, E., Mirzaei, H. R., Mahjoubin-Tehran, M., Rezaee, A., Sahebnasagh, R., Pourhanifeh, M. H., et al. (2019). Mesenchymal stem cell-derived exosomes: a new therapeutic approach to osteoarthritis? Stem Cell Res. Ther. 10:340. doi: 10.1186/s13287-019-1445-0

Min, H. K., Choi, J., Lee, S. Y., Seo, H. B., Jung, K., Na, H. S., et al. (2019). Protein inhibitor of activated STAT3 reduces peripheral arthritis and gut inflammation and regulates the Th17/Treg cell imbalance via STAT3 signaling in a mouse model of spondyloarthritis. J. Transl. Med. 17:18. doi: 10.1186/s12967-019-1774-x

Modinger, Y., Rapp, A. E., Vikman, A., Ren, Z. Z., Fischer, V., Bergdolt, S., et al. (2019). Reduced terminal complement complex formation in mice manifests in low bone mass and impaired fracture healing. Am. J. Pathol 189, 147-161. doi: 10.1016/j.ajpath.2018.09.011

Mulcahy, L. A., Pink, R. C., and Carter, D. R. (2014). Routes and mechanisms of extracellular vesicle uptake. J. Extracell Vesicles 3:24641. doi: 10.3402/jev.v3.24641

Murphy, N., Lynch, K., Lohan, P., Treacy, O., and Ritter, T. (2016). Mesenchymal stem cell therapy to promote corneal allograft survival: current status and pathway to clinical translation. Curr. Opin. Organ Transplant. 21, 559-567. doi: 10.1097/MOT.0000000000000360

Murray, P. J. (2017). Macrophage Polarization. Annu. Rev. Physiol. 79, 541-566. doi: 10.1146/annurev-physiol-022516-034339

Narayanaswamy, R., and Torchilin, V. P. (2019). Hydrogels and their applications in targeted drug delivery. Molecules 24:603. doi: 10.3390/molecules240 30603

Noack, M., and Miossec, P. (2014). Th17 and regulatory T cell balance in autoimmune and inflammatory diseases. Autoimmun. Rev. 13, 668-677. doi: $10.1016 /$ j.autrev.2013.12.004

Oishi, Y., and Manabe, I. (2018). Macrophages in inflammation, repair and regeneration. Int. Immunol. 30, 511-528. doi: 10.1093/intimm/dxy054

Oliva, N., Conde, J., Wang, K., and Artzi, N. (2017). Designing hydrogels for on-demand therapy. Acc. Chem. Res. 50, 669-679. doi: 10.1021 /acs.accounts.6b00536

Ozeki, N., Muneta, T., Koga, H., Nakagawa, Y., Mizuno, M., Tsuji, K., et al. (2016). Not single but periodic injections of synovial mesenchymal stem cells maintain viable cells in knees and inhibit osteoarthritis progression in rats. Osteoarthr. Cartilage 24, 1061-1070. doi: 10.1016/j.joca.2015.12.018

Park, H. J., Kim, J., Saima, F. T., Rhee, K. J., Hwang, S., Kim, M. Y., et al. (2018). Adipose-derived stem cells ameliorate colitis by suppression of inflammasome formation and regulation of M1-macrophage population through prostaglandin E2. Biochem. Biophys. Res. Commun. 498, 988-995. doi: 10.1016/j.bbrc.2018.03.096

Peter, J., Sabu, V., Aswathy, I. S., Krishnan, S., Lal Preethi, S. S., Simon, M., et al. (2020). Dietary amaranths modulate the immune response via balancing Th1/Th2 and Th17/Treg response in collagen-induced arthritis. Mol. Cell. Biochem. 472, 57-66. doi: 10.1007/s11010-02003783-x
Phan, A. T., Goldrath, A. W., and Glass, C. K. (2017). Metabolic and epigenetic coordination of $\mathrm{T}$ cell and macrophage immunity. Immunity 46, 714-729. doi: 10.1016/j.immuni.2017.04.016

Prockop, D. J., and Oh, J. Y. (2012). Mesenchymal stem/stromal cells (MSCs): role as guardians of inflammation. Mol. Ther. 20, 14-20. doi: 10.1038/mt.2011.211

Qi, C. L., Shan, Y. X., Wang, J., Ding, F. P., Zhao, D., Yang, T., et al. (2016). Circulating T helper 9 cells and increased serum interleukin-9 levels in patients with knee osteoarthritis. Clin. Exp. Pharmacol. P 43, 528-534. doi: 10.1111/1440-1681.12567

Rafei, M., Hsieh, J., Fortier, S., Li, M., Yuan, S., Birman, E., et al. (2008). Mesenchymal stromal cell-derived CCL2 suppresses plasma cell immunoglobulin production via STAT3 inactivation and PAX5 induction. Blood 112, 4991-4998. doi: 10.1182/blood-2008-07-166892

Raphael, I., Nalawade, S., Eagar, T. N., and Forsthuber, T. G. (2015). T cell subsets and their signature cytokines in autoimmune and inflammatory diseases. Cytokine 74, 5-17. doi: 10.1016/j.cyto.2014.09.011

Ren, G. W., Zhao, X., Zhang, L. Y., Zhang, J. M., L'Huillier, A., Ling, W. F., et al. (2010). Inflammatory cytokine-induced intercellular adhesion molecule- 1 and vascular cell adhesion molecule-1 in mesenchymal stem cells are critical for immunosuppression. J. Immunol. 184, 2321-2328. doi: 10.4049/jimmunol.0902023

Riau, A. K., Ong, H. S., G.,Yam, H. F., and Mehta, J. S. (2019). Sustained delivery system for stem cell-derived exosomes. Front. Pharmacol. 10:1368. doi: 10.3389/fphar.2019.01368

Riazifar, M., Mohammadi, M., Pone, E., Yeri, A., Lässer, C., Segaliny, A., et al. (2019). Stem cell-derived exosomes as nanotherapeutics for autoimmune and neurodegenerative disorders. ACS Nano 13, 6670-6688. doi: 10.1021/acsnano.9b01004

Samavedi, S., Diaz-Rodriguez, P., Erndt-Marino, J. D., and Hahn, M. S. (2017). A Three-dimensional chondrocyte-macrophage coculture system to probe inflammation in experimental osteoarthritis. Tissue Eng. Pt A 23, 101-114. doi: $10.1089 /$ ten.tea. 2016.0007

Sato, K., Ozaki, K., Oh, I., Meguro, A., Hatanaka, K., Nagai, T., et al. (2007). Nitric oxide plays a critical role in suppression of T-cell proliferation by mesenchymal stem cells. Blood 109, 228-234. doi: 10.1182/blood-2006-02-002246

Schena, F., Gambini, C., Gregorio, A., Mosconi, M., Reverberi, D., Gattorno, M., et al. (2010). Interferon- $\gamma$-dependent inhibition of B cell activation by bone marrow-derived mesenchymal stem cells in a murine model of systemic lupus erythematosus. Arthritis Rheum. 62, 2776-2786. doi: 10.1002/art.27560

Selmani, Z., Naji, A., Zidi, I., Favier, B., Gaiffe, E., Obert, L., et al. (2008). Human leukocyte antigen-G5 secretion by human mesenchymal stem cells is required to suppress $\mathrm{T}$ lymphocyte and natural killer function and to induce CD4(+)CD25(high)FOXP3(+) regulatory T cells. Stem Cells. 26, 212-222. doi: 10.1634/stemcells.2007-0554

Shen, B., Liu, J., Zhang, F., Wang, Y., Qin, Y., Zhou, Z., et al. (2016). CCR2 Positive exosome released by mesenchymal stem cells suppresses macrophage functions and alleviates ischemia/reperfusion-induced renal injury. Stem Cells Int. 2016:1240301. doi: 10.1155/2016/1240301

Shi, X., Chen, Q., and Wang, F. (2019). Mesenchymal stem cells for the treatment of ulcerative colitis: a systematic review and meta-analysis of experimental and clinical studies. Stem Cell Res. Ther. 10:266. doi: 10.1186/s13287-019-1336-4

Shi, Y., Wang, Y., Li, Q., Liu, K., Hou, J., Shao, C., et al. (2018). Immunoregulatory mechanisms of mesenchymal stem and stromal cells in inflammatory diseases. Nat. Rev. Nephrol. 14, 493-507. doi: 10.1038/s41581-018-0023-5

Smyth, T., Kullberg, M., Malik, N., Smith-Jones, P., Graner, M. W., and Anchordoquy, T. J. (2015). Biodistribution and delivery efficiency of unmodified tumor-derived exosomes. J. Control. Release 199, 145-155. doi: 10.1016/j.jconrel.2014.12.013

Song, Y., Dou, H., Li, X., Zhao, X., Li, Y., Liu, D., et al. (2017). Exosomal miR-146a contributes to the enhanced therapeutic efficacy of interleukin-1 $\beta$ primed mesenchymal stem cells against sepsis. Stem Cells 35, 1208-1221. doi: $10.1002 /$ stem.2564

Sun, G., Li, G., Li, D., Huang, W., Zhang, R., Zhang, H., et al. (2018). hucMSC derived exosomes promote functional recovery in spinal cord injury mice via attenuating inflammation. Mater. Sci. Eng. C Mater. Biol. Appl. 89, 194-204. doi: 10.1016/j.msec.2018.04.006

Tabera, S., Perez-Simon, J. A., Diez-Campelo, M., Sanchez-Abarca, L. I., Blanco, B., Lopez, A., et al. (2008). The effect of mesenchymal stem cells on the 
viability, proliferation and differentiation of B-lymphocytes. Haematologica 93 , 1301-1309. doi: 10.3324/haematol.12857

Ti, D., Hao, H., Tong, C., Liu, J., Dong, L., Zheng, J., et al. (2015). LPSpreconditioned mesenchymal stromal cells modify macrophage polarization for resolution of chronic inflammation via exosome-shuttled let-7b. J. Transl. Med. 13:308. doi: 10.1186/s12967-015-0642-6

Tomchuck, S. L., Zwezdaryk, K. J., Coffelt, S. B., Waterman, R. S., Danka, E. S., and Scandurro, A. B. (2008). Toll-like receptors on human mesenchymal stem cells drive their migration and immunomodulating responses. Stem Cells 26, 99-107. doi: 10.1634/stemcells.2007-0563

Utomo, L., Bastiaansen-Jenniskens, Y., Verhaar, J., and van Osch, G. J. (2016). Cartilage inflammation and degeneration is enhanced by proinflammatory (M1) macrophages in vitro, but not inhibited directly by anti-inflammatory (M2) macrophages. Osteoarthr. Cartilage 24, 2162-2170. doi: 10.1016/j.joca.2016.07.018

Vizoso, F. J., Eiro, N., Cid, S., Schneider, J., and Perez-Fernandez, R. (2017). Mesenchymal stem cell secretome: toward cell-free therapeutic strategies in regenerative medicine. Int. J. Mol. Sci. 18:1852. doi: 10.3390/ijms18091852

Wang, M., Yuan, Q., and Xie, L. (2018). Mesenchymal stem cell-based immunomodulation: properties and clinical application. Stem Cells Int. 2018:3057624. doi: 10.1155/2018/3057624

Wei, Z., Qiao, S., Zhao, J., Liu, Y., Li, Q., Wei, Z., et al. (2019). miRNA181a over-expression in mesenchymal stem cell-derived exosomes influenced inflammatory response after myocardial ischemia-reperfusion injury. Life Sci. 232:116632. doi: 10.1016/j.lff.2019.116632

Willis, G., Fernandez-Gonzalez, A., Anastas, J., Vitali, S., Liu, X., Ericsson, M., et al. (2018). Mesenchymal stromal cell exosomes ameliorate experimental bronchopulmonary dysplasia and restore lung function through macrophage immunomodulation. Am. J. Respir. Crit. Care Med. 197, 104-116. doi: $10.1164 / \mathrm{rccm} .201705-0925 \mathrm{OC}$

Willis, G. R., Kourembanas, S., and Mitsialis, S. A. (2017). Toward exosomebased therapeutics: isolation, heterogeneity, and fit-for-purpose potency. Front. Cardiovasc. Med. 4:63. doi: 10.3389/fcvm.2017.00063

Woodell-May, J. E., and Sommerfeld, S. D. (2020). Role of inflammation and the immune system in the progression of Osteoarthritis. J. Orthop. Res. 38, 253-257. doi: 10.1002/jor.24457

Wu, C., McNeill, J., Goon, K., Little, D., Kimmerling, K., Huebner, J., et al. (2017). Conditional macrophage depletion increases inflammation and does not inhibit the development of osteoarthritis in obese macrophage fas-induced apoptosistransgenic mice. Arthritis Rheumatol. 69, 1772-1783. doi: 10.1002/art.40161

Wu, C. L., Harasymowicz, N. S., Klimak, M. A., Collins, K. H., and Guilak, F. (2020). The role of macrophages in osteoarthritis and cartilage repair. Osteoarthr. Cartilage 28, 544-554. doi: 10.1016/j.joca.2019.12.007

Wu, X., Wang, Y., Xiao, Y., Crawford, R., Mao, X., and Prasadam, I. (2020). Extracellular vesicles: potential role in osteoarthritis regenerative medicine. J. Orthop. Translat. 21, 73-80. doi: 10.1016/j.jot.2019.10.012

Wynn, T. A., and Vannella, K. M. (2016). Macrophages in tissue repair, regeneration, and fibrosis. Immunity 44, 450-462. doi: 10.1016/j.immuni.2016.02.015

Yamashita, T., Takahashi, Y., and Takakura, Y. (2018). Possibility of exosome-based therapeutics and challenges in production of exosomes eligible for therapeutic application. Biol. Pharm. Bull. 41, 835-842. doi: 10.1248/bpb.b18-00133
Yang, Y., Zhang, X., Xu, M., Wu, X., Zhao, F., and Zhao, C. (2018). Quercetin attenuates collagen-induced arthritis by restoration of Th17/Treg balance and activation of Heme Oxygenase 1-mediated anti-inflammatory effect. Int. Immunopharmacol. 54, 153-162. doi: 10.1016/j.intimp.2017.11.013

Ylostalo, J. H., Bartosh, T. J., Coble, K., and Prockop, D. J. (2012). Human mesenchymal stem/stromal cells cultured as spheroids are self-activated to produce prostaglandin E2 that directs stimulated macrophages into an anti-inflammatory phenotype. Stem Cells 30, 2283-2296. doi: 10.1002/ stem.1191

Zhang, B., Yeo, R., Lai, R., Sim, E., Chin, K., and Lim, S. (2018). Mesenchymal stromal cell exosome-enhanced regulatory T-cell production through an antigen-presenting cell-mediated pathway. Cytotherapy 20, 687-696. doi: 10.1016/j.jcyt.2018.02.372

Zhang, H. Y., Lin, C. X., Zeng, C., Wang, Z. Y., Wang, H., Lu, J. S., et al. (2018). Synovial macrophage M1 polarisation exacerbates experimental osteoarthritis partially through R-spondin-2. Ann. Rheum. Dis. 77, 1524-1534. doi: 10.1136/annrheumdis-2018-213450

Zhang, K., Zhao, X., Chen, X., Wei, Y., Du, W., Wang, Y., et al. (2018). Enhanced therapeutic effects of mesenchymal stem cell-derived exosomes with an injectable hydrogel for hindlimb ischemia treatment. ACS Appl. Mater. Interfaces 10, 30081-30091. doi: 10.1021/acsami.8b08449

Zhang, S., Chuah, S. J., Lai, R. C., Hui, J. H. P., Lim, S. K., and Toh, W. S. (2018). MSC exosomes mediate cartilage repair by enhancing proliferation, attenuating apoptosis and modulating immune reactivity. Biomaterials 156, 16-27. doi: 10.1016/j.biomaterials.2017.11.028

Zhao, H., Shang, Q., Pan, Z., Bai, Y., Li, Z., Zhang, H., et al. (2018). Exosomes from adipose-derived stem cells attenuate adipose inflammation and obesity through polarizing M2 macrophages and beiging in white adipose tissue. Diabetes 67, 235-247. doi: $10.2337 / \mathrm{db} 17-0356$

Zhao, J., Li, X., Hu, J., Chen, F., Qiao, S., Sun, X., et al. (2019). Mesenchymal stromal cell-derived exosomes attenuate myocardial ischaemia-reperfusion injury through miR-182-regulated macrophage polarization. Cardiovasc. Res. 115, 1205-1216. doi: 10.1093/cvr/cvz040

Zhao, L., Chen, S., Yang, P., Cao, H., and Li, L. (2019). The role of mesenchymal stem cells in hematopoietic stem cell transplantation: prevention and treatment of graft-versus-host disease. Stem Cell Res. Ther. 10:182. doi: 10.1186/s13287-019-1287-9

Zhu, W., Zhang, X., Jiang, Y., Liu, X., Huang, L., Wei, Q., et al. (2020). Alterations in peripheral $\mathrm{T}$ cell and B cell subsets in patients with osteoarthritis. Clin. Rheumatol. 39, 523-532. doi: 10.1007/s10067-019-04768-y

Conflict of Interest: The authors declare that the research was conducted in the absence of any commercial or financial relationships that could be construed as a potential conflict of interest.

Copyright $\odot 2020$ Zhao, Zhao, Sun, Xing, Wang and Yang. This is an open-access article distributed under the terms of the Creative Commons Attribution License (CC $B Y)$. The use, distribution or reproduction in other forums is permitted, provided the original author(s) and the copyright owner(s) are credited and that the original publication in this journal is cited, in accordance with accepted academic practice. No use, distribution or reproduction is permitted which does not comply with these terms. 